\title{
Tratamento multidisciplinar para reabilitação estética anterior: relato de caso
}

Multidisciplinary treatment for previous aesthetic rehabilitation: case report

Tratamiento multidisciplinar para la rehabilitación estética anterior: informe de un caso

Jonathas Eduardo Virgilio PIASSI

Mestrando , Programa de Pós-Graduação em Odontologia, Faculdade de Odontologia de Araçatuba, UNESP - Universidade Estadual Paulista "Júlio de Mesquita Filho", 16015-050 Araçatuba - SP, Brasil https://orcid.org/0000-0002-9241-3456

Lucas Mendes SILVEIRA

Graduado em Odontologia pela Faculdade de Odontologia, Universidade Federal de Alfenas- UNIFAL, 37130-000 Alfenas-MG, Brasil

François Isnaldo DIAS CALDEIRA

Graduado em Odontologia pela Faculdade de Odontologia, Universidade Federal de Alfenas- UNIFAL, 37130-000 Alfenas-MG, Brasil https://orcid.org/0000-0002-4688-2059 Suzane Cristina PIGOSSI

Professora da Faculdade de Odontologia, Universidade Federal de Alfenas- UNIFAL, 37130-000 Alfenas-MG, Brasil https://orcid.org/0000-0001-7067-6119

Larissa Santana RODRIGUEZ

Professora da Faculdade de Odontologia, Universidade Federal de Alfenas- UNIFAL, 37130-000 Alfenas-MG, Brasil https://orcid.org/0000-0002-1928-2568

\section{Resumo}

O tratamento reabilitador tem a finalidade de restaurar a harmonia facial e com isso devolver a autoestima do indivíduo, reinserindo-o à sociedade. Este trabalho teve como objetivo descrever uma abordagem multidisciplinar envolvendo reabilitação estética anterior com prótese fixa adesiva associada à cirurgia periodontal estética. O presente relato de caso foi conduzido na Clínica Integrada I da Faculdade de Odontologia da Universidade Federal de Alfenas na qual a paciente procurou atendimento queixando-se da aparência do sorriso. No exame clínico foi observado que a paciente apresentava restaurações classe IV em resina composta com aspecto clínico insatisfatório, desarmonia dos zênites gengivais, encurtamento das coroas clínicas além da ausência do dente 22, substituído por prótese provisória splintada nos dentes adjacentes. Dessa forma, foi realizada a seguinte sequência clínica: clareamento dental superior/inferior e gengivoplastia na região superior anterior. Após a cicatrização foi realizado o preparo dentário, moldagem, confecção e cimentação de duas coroas unitárias em cerômero nos dentes 11 e 12 e a confecção de uma protése parcial fixa de 3 elementos (21, 22 e 23) em cerômero reforçado com fibra de vidro. Ao final do tratamento, foi possível restabelecer a função e estética em uma abordagem de baixo custo que garantiu a satisfação da paciente. Assim, a associação das diversas modalidades reabilitadoras da odontologia, como a periodontia, prótese e dentística proporcionou à paciente o restabelecimento dos padrões oclusais normais, recuperação da saúde periodontal, além de garantir um sorriso harmônico.

Descritores: Prótese Parcial Fixa; Estética Dentária; Gengivoplastia; Clareamento Dental.

\section{Abstract}

The rehabilitation treatment has the purpose of restoring facial harmony and patient's self-esteem. The aim of this case report was describe a multidisciplinary approach involving anterior aesthetic rehabilitation using fixed adhesive prosthesis associated with aesthetic periodontal surgery. The present case report was conducted in the Integrated Clinic II of the Federal University of Alfenas, to which the patient showed up complaining about her smile. The clinical examination showed class IV restorations in a composite resin with an unsatisfactory clinical appearance, gingival zeniths alteration, and an absence of the tooth 22 , replaced by a splint temporary prosthesis in the adjacent teeth. Thus, the following clinical sequence was performed upper and lower dental bleaching and anterior superior gingivoplasty. After healing, dental preparation, molding, confection and cementation of two ceramic crowns were performed on teeth 11 and 12 and the preparation of a fixed partial protection of 3 elements (21, 22 and 23) in glass fiber reinforced ceramics. At the end of treatment, it was possible to reestablish function and esthetics in a lowcost approach that ensured patient satisfaction. Thus, the association of various rehabilitation modalities of dentistry, such as periodontics, prosthesis, and dentistry, provided the patient with normal occlusal patterns, recovery of periodontal health, and a harmonious smile.

Descriptors: Denture, Partial, Fixed; Esthetics, Dental; Gingivoplasty; Tooth Bleaching.

\section{Resumen}

El tratamiento rehabilitador tiene como objetivo restablecer la armonía facial y con ello la autoestima del individuo, reinsertándolo en la sociedad. El objetivo de este trabajo es describir un enfoque multidisciplinar que incluye la rehabilitación estética anterior con prótesis adhesiva fija asociada a la cirugía periodontal cosmética. Este informe de caso fue realizado en la Clínica Integrada I de la Facultad de Odontología de la Universidad Federal de Alfenas, en la que el paciente buscó atención quejándose de la apariencia de la sonrisa. Durante el examen clínico se observó que la paciente tenía restauraciones de resina compuesta de clase IV con un aspecto clínico insatisfactorio, desarmonía de los ápices gingivales, acortamiento de las coronas clínicas y ausencia del diente 22, que fue sustituido por una prótesis provisional ferulizada en los dientes adyacentes. Así, se realizó la siguiente secuencia clínica: blanqueamiento dental superior/inferior y gingivoplastia en la región anterior superior. Después de la cicatrización, preparación dental, toma de impresión, fabricación y cementación de dos coronas individuales de cerómero en los dientes 11 y 12 y fabricación de una prótesis parcial fija de tres unidades $(21,22$ y 23) de cerómero reforzado con fibra de vidrio. Al final del tratamiento, fue posible restaurar la función y la estética con un enfoque de bajo coste que garantizaba la satisfacción del paciente. Así, la asociación de varias modalidades de odontología rehabilitadora, como la periodoncia, la prótesis y la odontología, proporcionó al paciente la restauración de los patrones oclusales normales, la recuperación de la salud periodontal, además de garantizar una sonrisa armoniosa.

Descriptores: Dentadura Parcial Fija; Estética Dental; Gingivoplastia; Blanqueamiento de Dientes.

INTRODUÇÃO

Ao olhar ou conversar com o indivíduo, os olhos do observador se alternam entre olhos e a boca, correspondendo às regiões mais expressivas da face. De fato, considerando-se os fatores que mais influenciam em uma estética facial agradável, a aparência do sorriso 
foi classificada em segundo lugar, perdendo somente para os olhos ${ }^{1,2}$.

Nesse sentido, a busca e a exigência por tratamentos que oferecem um alto padrão estético são cada vez mais frequentes nos consultórios odontológicos ${ }^{3}$. Em vista disso, a odontologia tem avançado consideravelmente para atender aos anseios estéticos dos pacientes, e vem desenvolvendo tratamentos que, além de recuperar a função mastigatória, tem como objetivo restabelecer a harmonia do sorriso ${ }^{1}$. Assim, a inter-relação entre as especialidades odontológicas tornou-se básica e indispensável no planejamento e execução de tratamentos mais previsíveis e abrangentes garantindo ao paciente melhora da autoestima, qualidade de vida e bem-estar ${ }^{2,4}$.

A harmonia do sorriso depende do perfeito equilíbrio entre os dentes, lábios e gengiva e estes combinados com os traços faciais de cada paciente ${ }^{5}$. Em várias situações clínicas, é necessária a manipulação dos tecidos gengivais para alcançar equilíbrio entre os elementos dentários, que consistem na estética branca, com os elementos periodontais, que compõem a estética vermelha ${ }^{1}$. Dessa forma, para se ter uma estética do sorriso agradável não depende apenas da harmonia de fatores dentários como cor, textura e forma dos dentes, mas também deve-se levar em consideração a arquitetura e coloração do tecido gengival.

Portanto, o objetivo do presente relato de caso foi descrever uma abordagem multidisciplinar incluindo o tratamento cirúrgico periodontal associado à reabilitação protética para restabelecimento da estética e função na região anterior da maxila.

CASO CLÍNICO

Paciente do gênero feminino, 45 anos, procurou atendimento na Clínica Integrada I da Universidade Federal de Alfenas queixando-se da aparência do sorriso. No exame clínico observou-se que a paciente apresentava restaurações classe IV em resina composta com aspecto clínico insatisfatório devido ao escurecimento e desgastes. O dente 12 encontrava-se com a região mesial fraturada. $\mathrm{Na}$ avaliação periodontal verificou-se desarmonia dos zênites gengivais da região dos primeiros pré-molares superiores do lado direito até primeiros pré-molares superiores do lado esquerdo. Além disto, foi verificado que as coroas clínicas deste grupo de dentes encontravam-se relativamente curtas. A paciente também apresentava ausência do dente 22 que estava substituído por uma prótese provisória splintada nos dentes adjacentes (Figura 1 A-D). Com base nesse exame clínico e na condição financeira da paciente, foi proposto a realização de um tratamento multidisciplinar incluindo gengivoplastia na região anterior superior, clareamento dentário e protéses fixas em cerômero nos dentes 12 ao 23 visando o restabelecimento estético e funcional.

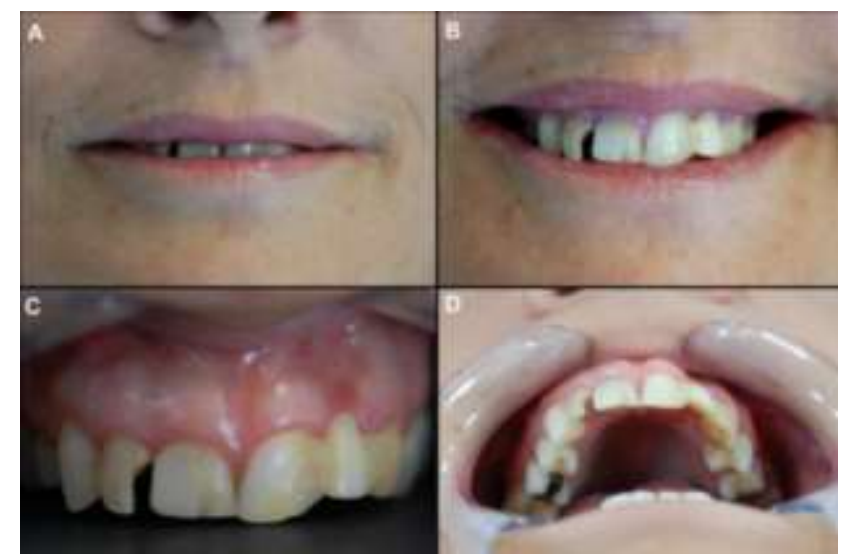

Figura 1: Aspecto inicial ao exame clínico. (A) Vista frontal com lábios entreabertos; (B) Vista frontal do sorriso, nota-se a fratura na região mesial do dente 12; (C) Vista frontal com afastador, destaque para coroas curtas e para o dente 22 splintado; (D) Aspecto da incisal dos dentes anteriores.

Iniciou-se a fase da reabilitação protética com a confecção do núcleo de preenchimento com pino de fibra de vidro no dente 12 com o canal radicular previamente tratado endodonticamente. Para isso foi realizado o preparo radicular com broca de Largo compatível com o diâmetro do pino selecionado. Após o tratamento da superfície do pino e do canal radicular, foi realizada a cimentação do pino com o cimento resinoso (Cimento Resinoso Dual RelyX ARC - 3M). O cimento foi inserido no interior do canal radicular seguido da colocação do pino de fibra de vidro. Por fim, foi feita a reconstrução coronária com resina composta cor A3 (Resina Filtek Z350 XT - 3M).

Após a finalização dessa etapa, foi realizado o clareamento dentário de consultório em duas sessões com o gel de clareador composto de peróxido de hidroxênio a 35\% (Clareador Whiteness HP, FGM, Brasil) que foi aplicado na superfície vestibular dos dentes por 15 minutos. Após 15 minutos, foi feita a remoção gel com sugador cirúrgico e realizada nova aplicação do gel clareador. Essa etapa foi repetida novamente totalizando 45 minutos de ação do gel por sessão. O mesmo procedimento foi realizado na segunda sessão de clareamento. Após a finalização das aplicações, foi realizada a moldagem dos dois arcos com alginato (Alginato Tipo II Jeltrate Dustless Dentsply) para confecção das próteses provisórias. 
Devido a presença de desarmonia dos zênites gengivais na região anterior superior foi proposto a realização do aumento de coroa clínica estético previamente a finalização da etapa restauradora. A sondagem transgengival foi feita utilizando uma sonda periodontal milimetrada (UNC15, Hu-Friedy Inc., Chicago, IL) para determinar a distância entre a Junção Cemento-Esmalte (JCE) e a Crista Ossea (CO). Após a sondagem observou-se que uma distância mínima de $2 \mathrm{~mm}$ estava presente sendo descartada a necessidade de osteotomia. Sendo assim, apenas a gengivoplastia foi feita nos dentes (12, 13, 14, 21, 23 e 24). Essa demarcação do zênite gengival foi feita por meio do exame visual baseando-se na proporção altura/largura da coroa (relação largura/comprimento ideal da coroa de 70,0$80,0 \%$ ) através de uma sonda periodontal. Cimento cirúrgico sem eugenol foi colocado na região operada (Pericem, Brasil).

Após 15 dias do procedimento cirúrgico, - preparo coronário para confecção dos provisórios foi realizado nos dentes 11, 12, 21 e 23 utilizando pontas diamantadas 3099, 3098, 3113,3118 (KG Sorensen, Brasil) (Figura 2A-D).

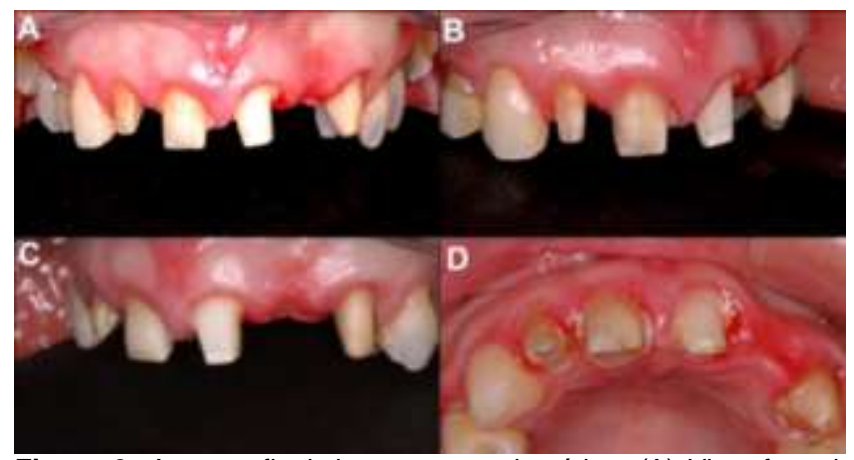

Figura 2: Aspecto final dos preparos dentários. (A) Vista frontal dos preparos; (B) Vista lateral direita dos preparos; (C) Vista lateral esquerda dos preparos; (D) Vista oclusal dos preparos.

Após finalizado os preparos, os provisórios confeccionados no laboratório foram reembasados e cimentados com cimento provisório (Cimento Provisório RelyX Temp NE 3M) (Figura 3 A-F). Após 45 dias do condicionamento tecidual realizado pelos provisórios, foi realizada a técnica de dupla moldagem utilizando silicona de adição (Silicona de Adição Express XT - 3M) para a moldagem dos preparos nos dentes 12, 11, 21 e 23. Fio retrator 000 (Ultrapack, Brasil) com hemostático (hemoliq, Maringa, Brasil) foi inserido nos sulcos gengivais dos dentes preparados, e procedeuse a seleção da moldeira e moldagem do arco superior com o material denso. O material leve foi injetado ao redor de todo o preparo utilizando uma seringa de automistura simultaneamente a remoção do fio retrator de número 000
(Ultrapack, Brasil) de cada dente. O material leve restante foi aplicado no centro da moldeira com o material denso, a moldeira foi reinserida em posição e esperada a polimerização do material.

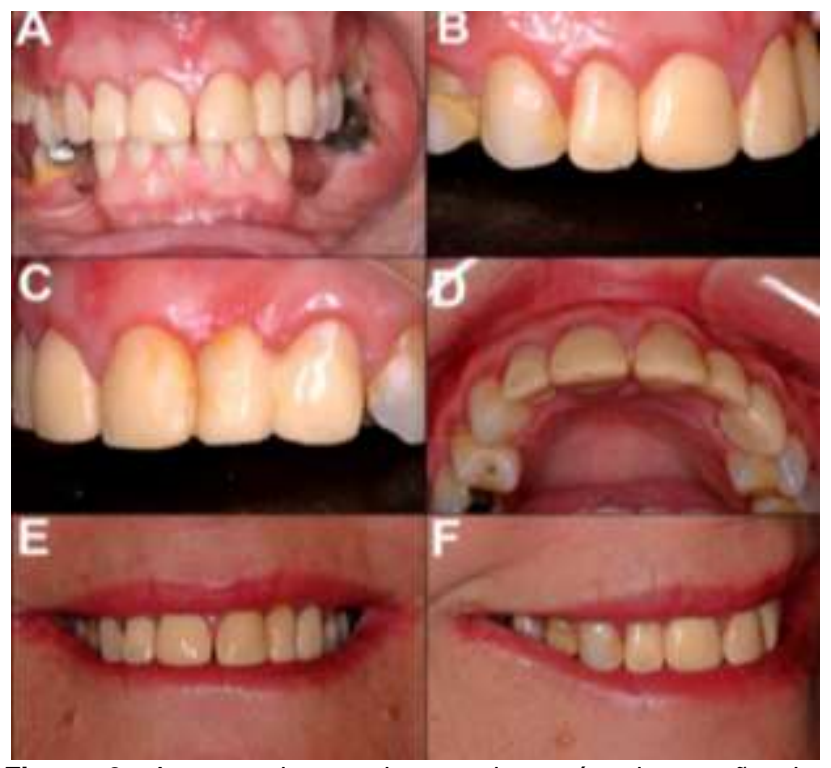

Figura 3: Aspecto da arcada superior após cimentação dos provisórios. (A) Adaptação dos provisórios ao tecido gengival e melhora no contorno da gengiva; (B; C) Vista lateral esquerda e direita dos provisórios, respectivamente; (D) Vista oclusal dos provisórios e adaptação gengival; (E; F) Aspectos dos dentes provisórios no sorriso.

A cimentação das próteses definitivas com cimento resinoso dual (Cimento Resinoso Dual RelyX U200 - 3M) foi realizada após 20 dias, na qual foram cimentadas duas coroas unitárias de cerômero nos dentes 12 e 11 e uma prótese fixa de três elementos de cerômero reforçado com fibra de vidro (CRFV) nos dentes 21 ao 23. Para este procedimento, foi realizada a confecção de um suporte em silicona de condensação densa para reter os elementos protéticos e facilitar o preparo das suas superfícies. O preparo da superfície das peças foi realizado com Ácido Fosfórico 37\% (Attaque Gel Biodinâmica, Brasil) por 30 segundos. Em seguida foi realizada lavagem, secagem, aplicação de Silano (Prosil- Joinville, Brasil) e Adesivo (Prosil- Joinville, Brasil) (Figura 4 A-F). Seguiu-se o preparo de superfície dos dentes com aplicação de Ácido Fosfórico $37 \%$ por 30 segundos, lavagem, secagem, proteção dos dentes adjacentes com fita Teflon, aplicação de Adesivo (Adper Single Bond 2 3M) e fotoativação por 20 segundos.

A sequência de cimentação iniciou-se com protése parcial fixa. Foi realizada a amarria no elemento 22 com fio dental para facilitar a remoção de resíduos do material cimentador na região do rebordo alveolar (Figura 5A). A superfície interna da prótese foi preenchida com cimento resinoso (Rely X U200 Dual, 3M, Brasil) (Figura 5B-5C). Os pilares foram inseridos e 
adaptados ao remanescente dentário e o excesso foi removido com sugador endodôntico associado ao uso de pincel para refinar a limpeza nas faces livres (Figura 5D-F).
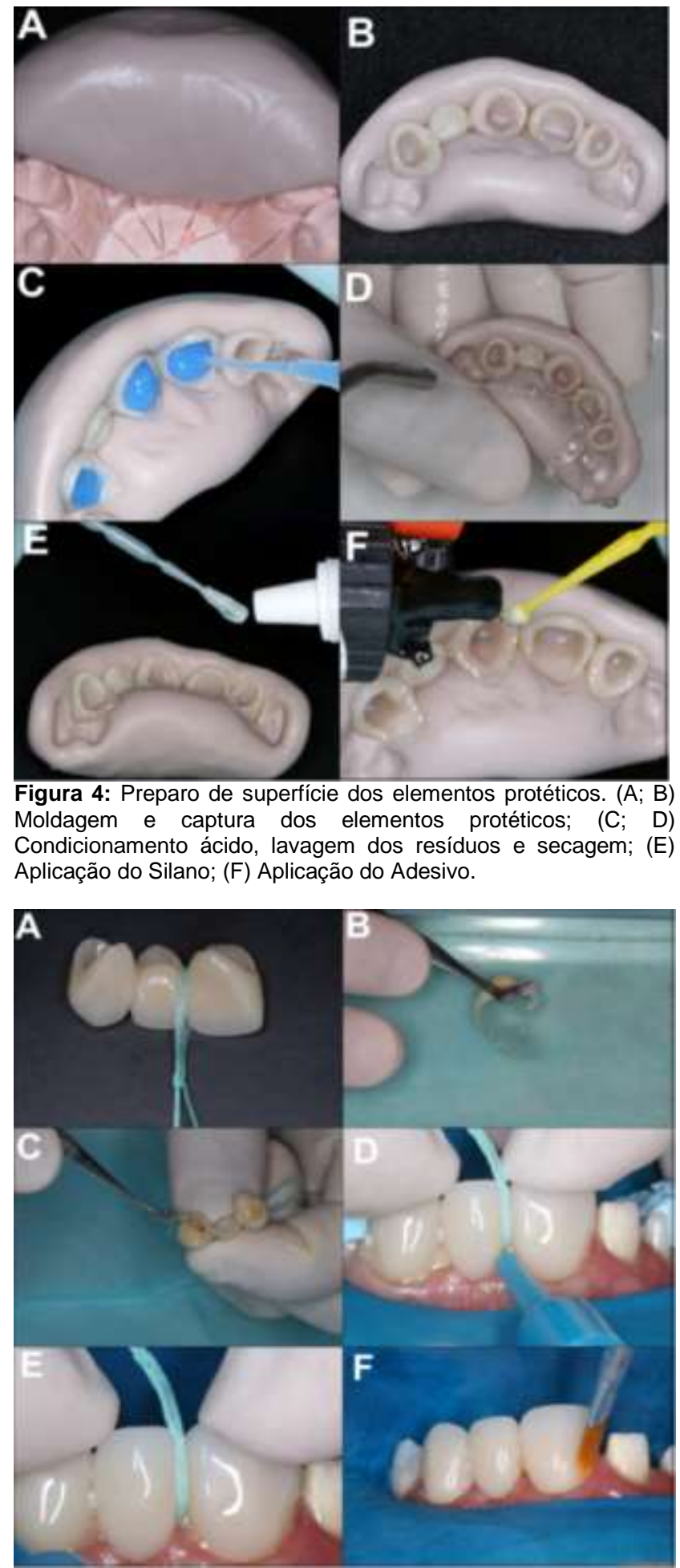

Figura 5: Sequência de cimentação da prótese parcial fixa. (A) Amarria com fio dental para facilitação da limpeza dos resíduos do cimento; (B; C) Aplicação do cimento resinoso; (D; E) Pôntico levado em posição mantido sob pressão digital. Detalhe para a utilização do sugador endodôntico como auxiliar na remoção dos excessos do cimento juntamente com o fio dental. (F) Remoção de resíduos de cimento com pincel.

Uma fotoativação breve de 5 segundos foi aplicada para permitir a remoção de possíveis excessos do cimento na distal do dente 23. Os dentes 11 e 12 seguiram a mesma sequência de cimentação acima. Ao final da cimentação foi realizada a fotoativação final de todos os dentes por 1 minuto em cada face dos elementos protéticos. $O$ aspecto final imediato após cimentação é ilustrado na (Figura 6 A-F) após o tratamento estético proposto.

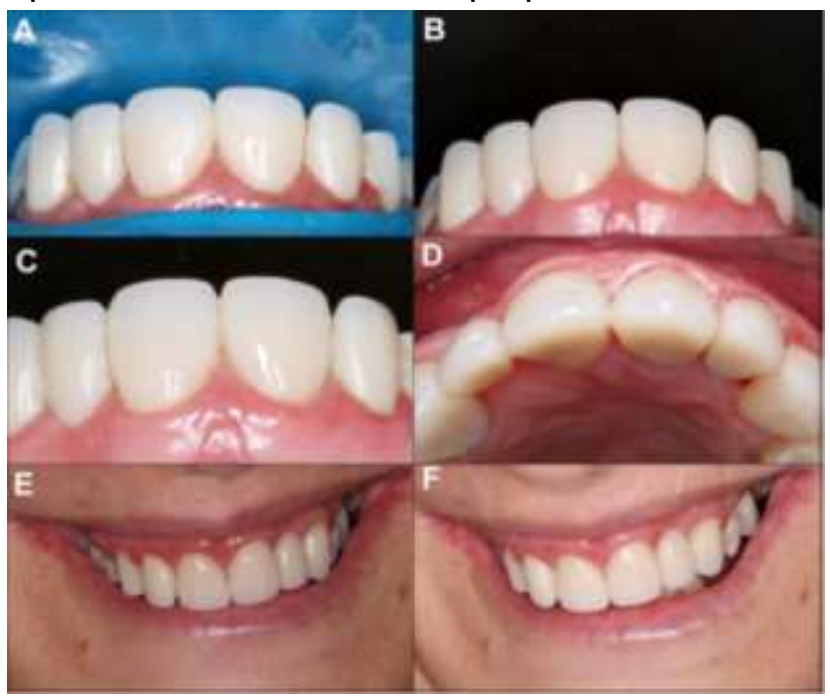

Figura 6: Aspecto final após cimentação definitiva. (A; D) Adaptação e correção estética proporcionada pelos elementos protéticos; (E; F) Aspecto do novo sorriso da paciente logo após a cimentação.

\section{DISCUSSÃO}

O presente relato de caso abordou como modalidade de tratamento a reabilitação da estética dentária anterior. Por meio da associação de diversas especialidades da Odontologia, o atendimento visou reestabelecer - quesito funcional assim como proporcionar maior harmonia estética ao sorriso da paciente. A abordagem multidisciplinar envolvendo procedimentos restauradores e cirúrgicos periodontais se justifica pela presença de restaurações insatisfatórias, ausência de elementos dentários e alterações no zênite gengival. Ao final do tratamento estético foi possível restabelecer a função e estética em uma abordagem de baixo custo que garantiu a satisfação da paciente. Além disso, as técnicas utilizadas devolveram a confiança da paciente com relação ao sorriso, impactando diretamente em sua qualidade de vida ${ }^{3,4,6}$.

Por se tratar de um procedimento conservador e de elevado potencial estético, 0 uso do clareamento realizado no consultório foi indicado nesse caso com a finalidade de se alcançar uma melhora na coloração dos dentes anteriores $^{7}$. O emprego da técnica foi recomendado para que as restaurações em resina composta pudessem ser realizadas posteriormente com coloração mais clara. Entretanto, devido a quantidade reduzida de remanescente dentário após a remoção das resinas antigas, optou-se pela reabilitação com prótese fixa. $\mathrm{O}$ clareamento realizado 
integralmente no consultório garantiu um resultado mais rápido, pois os produtos utilizados apresentam concentrações mais altas de peróxido do que os utilizados no clareamento caseiro $^{8,9}$. O uso dessas concentrações muito superiores às utilizadas no protocolo domiciliar poderia aumentar o risco e da intensidade da sensibilidade dentária para o clareamento de consultório. No entanto, De Geus et al. ${ }^{9}$ em uma revisão sistemática com meta-análise demonstrou que não houve diferença significativa entre o clareamento caseiro e de consultório em relação a ocorrência de sensibilidade dentária ou eficácia do clareamento. Ressalta-se que no presente caso a paciente não relatou a presença de sensibilidade dentária após a finalização das duas sessões de clareamento.

Outro procedimento realizado neste caso foi o aumento de coroa clínica-estético (ACCE) na região anterior superior. Esta técnica visa o restabelecimento da adesão tecidual supraóssea permitindo que outros procedimentos restauradores sejam realizados sem maiores danos ao periodonto, e, além disso, sugere-se que uma distância de $2 \mathrm{~mm}$ correspondente a adesão tecidual supraóssea e $1 \mathrm{~mm}$ para a profundidade do sulco devem ser restabelecidas para garantir a saúde periodontal e uma menor recidiva do tecido gengival ao seu posicionamento original após o procedimento de $\mathrm{ACCE}^{3,10}$. Neste caso clínico uma distância mínima de $2 \mathrm{~mm}$ entre a JCE e a CO foi observada durante a sondagem transgengival (ST) descartando a necessidade de remoção óssea. Após um período de 3 meses após a cirurgia, observou-se que a margem gengival manteve-se em uma posição adequada e harmônica confirmando a eficácia do procedimento.

Apesar da literatura atual sugerir novas abordagens que utilizam o planejamento digital para determinar a forma e contorno dos dentes, bem como a posição final da margem gengival ${ }^{11}$, Nesta situação clínica optou-se por uma abordagem clássica baseando-se no exame visual para a realização do procedimento cirúrgico. Além disso, a ST foi utilizada para detectar a localização da JEC e assim calcular a distância CO-JEC e a dimensão real da coroa clínica $^{12}$. A eficácia desse método de diagnóstico foi comprovada em estudos que demostraram que a ST é um método preciso para determinar os níveis da $\mathrm{CO}$ após comparar as medidas obtidas na ST e o nível da CO após o deslocamento do retalho ${ }^{13}$. No entanto, o uso da tomografia computadorizada de feixe cônico de tecido mole (TCFC-TM) tem sido proposto para determinar a dimensão da unidade dentogengival (inserção epitelial e conjuntiva) ${ }^{14}$. Além disso, a TCFC-TM também exibe estruturas de tecido duro (ossos e dentes) determinando com precisão a quantidade de tecido gengival que cobre o esmalte e pode ser removido sem a ocorrência de uma recessão gengival. Outra vantagem do uso da TC para o planejamento do ACE é a possibilidade de estimar se a ressecção óssea é necessária tornando o procedimento cirúrgico mais preciso e previsível. Neste caso, a realização da TCFCTM não foi possível devido ao elevado custo desse exame.

As próteses parciais fixas livres de metal têm se tornado alternativas viáveis para reabilitação de dentes ausentes posteriores e anteriores, em detrimento do uso das ligas metálicas tendo em vista seu o potencial estético e sua estabilidade mecânica ${ }^{15}$. Os materiais utilizados na confecção desse tipo de prótese são dos mais diversos e possuem variações no seu potencial estético, mecânico e também no seu valor de mercado. Neste contexto, se destacam os materiais ceroméricos, principalmente quando associado a um reforço de fibra de vidro. Nesse relato foram realizadas coroa unitárias em cerômeros nos dentes 12 e 11 e uma PF de 3 elementos utilizando CRFV no dentes 21, 22 e 23. Esses materiais de escolha foram decorrentes da falta de tecido dentário remanescente suficiente para confecção de restaurações diretas e da elevada exigência estética do caso associado à necessidade de um reforço mecânico na região dos dentes 21, 22 e 23 devido à ausência do dente 22. Outro fator determinante na escolha desse material foi o baixo custo do material em comparação as restaurações em cerâmica. O uso do CRFV garante uma alta sobrevida global com resultados de desempenho previsíveis mesmo em regiões com elevada carga oclusal $^{16}$. No entanto, a principal limitação do uso clínico do CRFV inclui a fraqueza da interface entre a fibra e a matriz orgânica. A hidrólise e degradação intraorais enfraquecem essa interface e a falha pode ocorrer. As principais falhas incluem as fraturas e delaminação, mas tais eventos podem ser facilmente reparados com materiais compostos de resina ${ }^{17}$.

Com esse relato de caso foi possível observar que seguindo as diretrizes de um planejamento adequado e visando a abordagem criteriosa das etapas operatórias é possível alcançar o sucesso funcional e estético sem a utilização de procedimentos de alto custo. Sendo assim, a associação das diversas 
modalidades reabilitadoras da Odontologia, como a Periodontia, Prótese e Dentística proporciona aos pacientes o restabelecimento dos padrões oclusais normais, recuperar a saúde periodontal, além de garantir um sorriso harmônico. Deste modo, a utilização de materiais que apresentavam propriedades de reforço, baixo custo e qualidade estética aliados a técnicas cirúrgicas que proporcionaram resultados imediatos, foram de grande valia para que a paciente retomasse rapidamente sua autoestima e adquirisse confiança no tratamento.

CONCLUSÃO

Concluiu-se com este caso que a abordagem multidisciplinar proposta incluindo o tratamento cirúrgico periodontal associado à reabilitação protética garantiu 0 restabelecimento da estética e função na região anterior da maxila com elevada satisfação da paciente.

REFERÊNCIAS

1. Al-Harbi F, Ahmad I. A guide to minimally invasive crown lengthening and tooth preparation for rehabilitating pink and white aesthetics. Br Dent J. 2018;224(4):228-34.

2. Witt M, Flores-Mir C. Laypeople's preferences regarding frontal dentofacial esthetics: toothrelated factors. JAMA. 2011;142(6):635-45.

3. Deas DE, Mackey SA, Sagun RS, Hancock RH, Gruwell SF, Campbell CM. Crown lengthening in the maxillary anterior region: a 6-month prospective clinical study. Int $\mathrm{J}$ Periodontics Restorative Dent. 2014;34(3):365-73.

4. Ngoc VTN, Tran DK, Dung TM, Anh NV, Nga VT, Anh LQ et al. Perceptions of dentists and non-professionals on some dental factors affecting smile aesthetics: a study from Vietnam. Int $\mathrm{J}$ Environ Res Public Health. 2020;17(5):1638.

5. Hamasni FM, Majzoub ZAK. Effect of patientand surgery-related factors on supracrestal tissue reestablishment after crown lengthening procedure. Quintessence Int. 2019;50(10):792801.

6. Cervino G, Fiorillo L, Arzukanyan AV, Spagnuolo G, Cicciu M. Dental restorative digital workflow: digital smile design from aesthetic to function. Dent $\mathrm{J}$ (Basel). 2019;7(2):30.

7. Sulieman MAM. An overview of tooth-bleaching techniques: chemistry, safety and efficacy. Periodontology 2000. 2008;48:148-69,

8. Joiner $A$. The bleaching of teeth: a review of the literature. J Dent. 2006;34(7):412-19.

9. de Geus JL, Wambier LM, Kossatz S, Loguercio AD, Reis A. At-home vs In-office Bleaching: A Systematic Review and Metaanalysis. Operative Dent. 2016;41(4):341-56.
10. Ribeiro FV, Hirata DY, Reis AF, Santos VR, Miranda TS, Faveri $M$ et al. Open-flap versus flapless esthetic crown lengthening: 12-month clinical outcomes of a randomized controlled clinical trial. J Periodontol. 2014;85(4):536-44.

11. Arias DM, Trushkowsky RD, Brea LM, David SB. Treatment of the Patient with Gummy Smile in Conjunction with Digital Smile Approach. Dent Clin North Ame. 2015;59(3):703-16.

12. De Rouck T, Eghbali R, Collys $\mathrm{K}$, De Bruyn $\mathrm{H}$, Cosyn J. The gingival biotype revisited: transparency of the periodontal probe through the gingival margin as a method to discriminate thin from thick gingiva. J Clin Periodontol. 2009; 36(5):428-33.

13. Perez JR, Smukler H, Nunn ME. Clinical evaluation of the supraosseous gingivae before and after crown lengthening. J Periodontol. 2007;78(6):1023-30.

14. Januario AL, Barriviera M, Duarte WR. Soft tissue cone-beam computed tomography: a novel method for the measurement of gingival tissue and the dimensions of the dentogingival unit. J Esth Restorative Dentistry. 2008;20(6):366-73; discussion 74

15. Takahashi CU, De Cara AA, Contin I. Resistance to fracture of direct restorations with cuspal coverage in endodontically treated upper bicuspids. Braz Oral Res. 2001;15(3):247-51.

16. Ahmed KE, Li KY, Murray CA. Longevity of fiber-reinforced composite fixed partial dentures (FRC FPD)-Systematic review. J Dent. 2017;61:1-11.

17. Frese C, Decker C, Rebholz J, Stucke K, Staehle HJ, Wolff D. Original and repair bond strength of fiber-reinforced composites in vitro. Dental Mater.2014;30(4):456-62.

CONFLITO DE INTERESSES

Os autores declaram não haver conflitos de interesse

AUTOR PARA CORRESPONDÊNCIA

\section{Larissa Santana Rodriguez}

Faculdade de Odontologia da Universidade Federal de Alfenas (UNIFAL-MG)

Rua Gabriel Monteiro da Silva, 700, Centro,

37.130-000 Alfenas- MG, Brasil

E-mail: larissa.rodriguez@unifal-mg.edu.br

Submetido em 08/04/2021 Aceito em 16/07/2021 